\title{
Rapid Induction of Osteogenic Markers in Mesenchymal Stem Cells by Adipose- Derived Stromal Vascular Fraction Cells
}

\author{
Jung-Won Choi ${ }^{a, b}$ Sunhye Shinc Chang Youn Lee ${ }^{c}$ Jiyun Lee ${ }^{d}$ Hyang-Hee Seo $^{d}$ \\ Soyeon Lim ${ }^{\mathrm{a}, e}$ Seahyoung Lee ${ }^{\mathrm{a}, \mathrm{e}}$ Il-Kwon Kim ${ }^{\mathrm{a}, \mathrm{f}}$ Hoon-Bum Lee ${ }^{\mathrm{g}}$ \\ Sang Woo Kim ${ }^{\mathrm{a}, \mathrm{e}}$ Ki-Chul Hwanga,e \\ anstitute for Bio-Medical Convergence, College of Medicine, Catholic Kwandong University, \\ Gangneung-si, Gangwon-do, 'bepartment of Health and Environment, College of Engineering, Catholic \\ Kwandong University, Gangneung-si, Gangwon-do, 'Department of Integrated Omics for Biomedical \\ Sciences, Graduate School, Yonsei University, Seoul, 'Brain Korea 21 PLUS Project for Medical Science, \\ Yonsei University College of Medicine, Seoul, e'Catholic Kwandong University, International St. Mary's \\ Hospital, Incheon Metropolitan City, ${ }^{f}$ Cell Therapy Center, Catholic Kwandong University International \\ St. Mary's Hospital, Incheon Metropolitan City , ${ }^{9}$ Department of Plastic and Reconstructive Surgery, \\ Catholic Kwandong University, International St. Mary's Hospital, Incheon Metropolitan City, Republic of \\ Korea
}

\section{Key Words}

Adipose-derived stromal vascular fraction cells - Bone marrow-derived mesenchymal stem cells $\bullet$ Osteogenesis - Transforming growth factor beta $\bullet$ Bone morphogenetic protein $2 \cdot$ Coculture system

\begin{abstract}
Background/Aims: Stromal vascular fraction (SVF) cells are a mixed cell population, and their regenerative capacity has been validated in various therapeutic models. The purpose of this study was to investigate the regenerative mechanisms utilized by implanted SVF cells. Using an in vitro co-culture system, we sought to determine whether SVF implantation into impaired tissue affects endogenous mesenchymal stem cell (MSC) differentiation; MSCs can differentiate into a variety of cell types, and they have a strong regenerative capacity despite their low numbers in impaired tissue. Methods: Adipose-derived SVF cells obtained from four donors were co-cultured with bone marrow-derived MSCs, and the differential expression of osteogenic markers and osteogenic differentiation inducers over time was analyzed in monocultured MSCs and MSCs co-cultured with SVF cells. Results: The co-cultivation of MSCs with SVF cells significantly and mutually induced the expression of osteogenic-specific markers via paracrine and/or autocrine regulation but did not induce adipocyte, chondrocyte or myoblast marker expression. More surprisingly, subsequent osteogenesis and/or comparable effects were rapidly induced within $48 \mathrm{~h}$. Conclusion: To the best of our knowledge, this is the first study in which osteogenesis and/or comparable effects were rapidly induced in bone marrow-

J.-W. Choi and S. Shin contributed equally to this work.

Ki-Chul Hwang

and Sang Woo Kim




\section{Cellular Physiology Cell Physiol Biochem 2017;44:53-65 and BiOChemistry Published online: November 03, 2017 \begin{tabular}{l|l} 
DOI: 10.1159/000484582 2017 The Author(s). Published by S. Karger AG, Basel \\
www.karger.com/cpb
\end{tabular} \\ Choi et al.: Rapid Osteogenic Differentiation of Mesenchymal Stem Cells}

derived MSCs and adipose-derived SVF cells through co-cultivation. Our findings suggest that the positive effects of SVF implantation into impaired bone may be attributed to the rapid induction of MSC osteogenesis, and the transplantation of co-cultured and preconditioned SVF cells and/or MSCs may be more effective than the transplantation of untreated cells for the treatment of bone defects.

(C) 2017 The Author(s)

Published by S. Karger AG, Basel

\section{Introduction}

Adult mesenchymal stem cells (MSCs) can be isolated from bone marrow [1], skeletal muscles [2], adipose tissues [3], synovial membranes [4], trabecular bone [5] or adenoid tissues [6]. MSCs were first isolated from bone marrow, which is still a commonly used source for MSC isolation because they are easy to harvest and have potent differentiation ability [7-10]. Bone marrow-derived MSCs can differentiate into multiple lineages, including osteoblasts, chondrocytes, adipocytes, tenocytes and vascular smooth muscle cells [7, 11], and they support hematopoiesis in vivo upon de novo bone formation [12].

Adipose-derived stem cells (ASCs), which are a form of MSCs, have been intensely studied due to their multipotent differentiation capacity, paracrine effects and implications for regenerative medicine [13-15]. A recent shift of focus has directed attention away from the study of ASCs to that of the heterogeneous mixed cell population from which they are derived, the stromal vascular fraction (SVF) $[16,17]$. SVF cells, which are traditionally isolated through enzymatic processing, contain MSCs, endothelial (progenitor) cells, immune cells, smooth muscle cells, pericytes and other stromal components [18]. SVF treatment has been shown to provide therapeutic effects similar to those of ASC treatment in osteochondral defects and myocardial infarction $[19,20]$, and SVF cells have been demonstrated to have similar neuroprotective effects and greater immunomodulatory properties than ASCs in experimental chronic autoimmune encephalitis studies [21]. The regenerative capacity of SVF cells has been validated in various therapeutic models, such as fat grafting, multiple sclerosis, burn injury, diabetes, radiation, Crohn's disease, cardiac disease and bone defect models $[13,14]$. When applied to these models, SVF cells have shown angiogenic, immunomodulatory, differentiation, proliferation, and pro-survival properties that are important for regeneration and repair [13]. These regenerative properties of SVF cells can be attributed to the heterogeneity of the cell population, which likely employs numerous mechanisms to facilitate regeneration [13]. Despite these attractive advantages of SVF implantation in clinical interventions, the status of recent clinical studies for many diseases has not been fully evaluated [22].

The final purpose of this study was to investigate some of the regenerative mechanisms utilized by implanted SVF cells. Here, using an in vitro co-culture system, we sought to determine whether SVF implantation into impaired tissue affects endogenous MSC differentiation, as MSCs can differentiate into a variety of cell types and have a strong regenerative capacity despite their low numbers in impaired tissue. Furthermore, adiposederived SVF cells obtained from four donors were co-cultured with bone marrow-derived MSCs, and the differential expression of osteogenic markers and osteogenic differentiation factors over time was examined over time in mono-cultured MSCs and MSCs co-cultured with SVF cells. Surprisingly, we observed that both MSCs and SVF cells significantly and mutually enhanced the expression levels of osteogenic-specific markers via paracrine and/ or autocrine regulation but did not enhance adipocyte, chondrocyte or myoblast marker expression. More surprisingly, subsequent osteogenesis and/or comparable effects were rapidly induced within $48 \mathrm{~h}$. This duration is very rapid compared with the typical time required for the in vitro osteogenic differentiation of MSCs. To the best of our knowledge, this work is the first to report the rapid induction of osteogenesis and/or comparable effects in bone marrow-derived MSCs through co-cultivation with adipose-derived SVF cells. This finding provides new insights into the potential clinical applications of adipose-derived SVF cells and/or bone marrow-derived MSCs for bone diseases. 


\section{Cellular Physiology Cell Physiol Biochem 2017;44:53-65 \begin{tabular}{l|l|l} 
and Biochemistry Published online: November 03, 2017 & $\begin{array}{l}\text { (c) } 2017 \text { The Author(s). Published by S. Karger AG, Basel } \\
\text { www.karger.com/cpb }\end{array}$
\end{tabular} \\ Choi et al.: Rapid Osteogenic Differentiation of Mesenchymal Stem Cells}

\section{Materials and Methods}

Adipose tissue harvesting and isolation of SVF cells

Human adipose tissue samples for SVF isolation were obtained from four donors who were recruited at International St. Mary's Hospital of the Catholic Kwandong University, and the donor information is shown in Table 1. The study protocol was approved by the ethics review committee of the Institutional Review Board, College of Medicine, Catholic Kwandong University. Liposuction was performed under general anesthesia and sterile conditions, and the adipose tissue samples were harvested from the abdominal wall using gentle manual techniques. SVF cells were isolated from adipose tissues using a SmartX kit (Dongkoo Bio \& Pharma Co., Seoul, South Korea) according to the manufacturer's instructions. Briefly, water, tumescent tissue and oil was removed from the isolated adipose tissue, and then the tissue was digested with $0.075 \%$ collagenase type I at $37^{\circ} \mathrm{C}$ for $30 \mathrm{~min}$. Digested tissue was filtered through a $75-\mu \mathrm{m}$ strainer to remove residual tissue, and the filtered cell suspension was centrifuged at 2, 000 × $\mathrm{g}$ for $3 \mathrm{~min}$ and washed with phosphate-buffered saline (PBS; HyClone, Logan, UT, USA) three times. Total and live cell counts were performed using a Nucleocounter ${ }^{\circledR}$ NC- $200^{\mathrm{TM}}$ automated cell counter (Chemometec, Denmark).

Culture of human adipose-derived SVF cells and bone marrow-derived MSCS

Isolated SVF cells and MSCs (ATCC, Manassas, Virginia, USA) were cultured in Dulbecco's modified Eagle's medium (DMEM; Gibco, Waltham, Massachusetts, USA) containing 10\% fetal bovine serum (FBS) (Gibco) and $1 \%$ penicillin/streptomycin in a humidified atmosphere with $5 \% \mathrm{CO}_{2}$ at $37^{\circ} \mathrm{C}$. SVF cells (passage 3) and MSCs (passage 8) were used for all experiments.

\section{Co-culture of SVF cells and MSCS}

MSCs were plated $24 \mathrm{~h}$ prior to co-culture at a density of $5 \times 10^{4}$ cells $/ \mathrm{cm}^{2}$ in 24 -well and 6-well plate, and individual SVF cells from four donors were plated on trans-well inserts with a $0.4-\mu \mathrm{m}$ porous translucent PET membrane (FALCON, Pittston, PA, USA) at a cell density identical to that of MSCs. After 12, 24 and $48 \mathrm{~h}$, SVF cells and MSCs were harvested for analysis. Western blot analysis was used to detect secreted proteins in the culture medium (serum-free medium) after up to $48 \mathrm{~h}$ of culture.

\section{Alkaline phosphatase (ALP) staining}

An ALP Staining Kit (Cosmo Bio, Tokyo, Japan) was used for the ALP staining of MSCs co-cultured with SVF cells. The MSCs in a 24-well plate were fixed in 10\% formalin (Sigma-Aldrich, St. Louis, MO, USA) for $20 \mathrm{~min}$ at room temperature after being washed with PBS and then deionized water three times each. Chromogenic substrate dissolved in substrate-containing buffer (kit component) was added to each well, and after incubation at $37^{\circ} \mathrm{C}$ for $20 \mathrm{~min}$, the cells were washed with deionized water to stop the reaction. A digital camera (eXcope T300, Olympus, Tokyo) attached to an inverted phase-contrast microscope (CKX-41, Olympus) was used for microscopic observation.

\section{ALP activity}

Co-cultured MSCs with SVF cells in a 24-well plate were fixed with an acetone/ethanol (Sigma-Aldrich) mixture $(50: 50, \mathrm{v} / \mathrm{v})$ for $20 \mathrm{~min}$ at room temperature after being washed with PBS and then deionized water three times each. The MSCs were incubated in a substrate solution (0.1 M diethanolamine (Sigma-Aldrich), $1 \mathrm{mM} \mathrm{MgCl}$ (Sigma-Aldrich), and $10 \mathrm{mg} / \mathrm{ml} \mathrm{p}$-nitrophenyl phosphate (Sigma-Aldrich)) for $20 \mathrm{~min}$ at $37^{\circ} \mathrm{C}$, the reaction was stopped by adding $5 \mathrm{M} \mathrm{NaOH}$ (Sigma-Aldrich), and absorbance was measured at $405 \mathrm{~nm}$ using a microplate reader (Multiskan FC; Thermo Fisher Scientific, Vantaa, Finland).

RNA isolation, reverse transcription (RT)-PCR and quantitative real-time PCR ( $P$ PCR)

Total RNA was isolated from MSCs and SVF cells using TRIzol Reagent Solution (Life Technologies, Frederick, Maryland, USA) according to the manufacturer's instructions. Oligo dT-primed cDNA was 


\section{Cellular Physiology Cell Physiol Biochem 2017;44:53-65

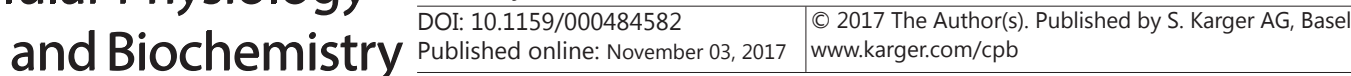 \\ Choi et al.: Rapid Osteogenic Differentiation of Mesenchymal Stem Cells}

synthesized from total RNA using a Maxime RT PreMix kit (iNtRON Biotechnology, Seongnam, Korea). The expression of each gene transcript was quantified by qPCR using an Applied Biosystems StepOnePlus real-time PCR System (Foster City, CA, USA) with a SYBR Green Dye system (SYBR Premix Ex Taq, Tli RNase Plus and ROX reference dye (Takara Bio Inc. Foster City, CA, USA)). All values are shown as the normalized target gene expression level (fold change; $2^{-\Delta \Delta \mathrm{Ct}}$ ) relative to the GAPDH transcript level. Primers were designed using Primer3 and BLAST, and the primer set sequences are listed in Table 2.

Western blot analysis

The MSCs and SVF cells were washed with PBS and lysed with RIPA buffer (Cell signaling Technology, Danvers, Massachusetts, USA) containing $1 \%$ phosphatase inhibitors (SigmaAldrich) and $1 \%$ protease inhibitors (SigmaAldrich). Conditioned medium (CM) from the cells was centrifuged for $30 \mathrm{~min}$ at $1,000 \times \mathrm{g}$ and $4^{\circ} \mathrm{C}$ to remove cell debris and then concentrated using an Amicon Ultra Centrifugal Filter (Millipore Corporation, Bedford, MA, USA) with a membrane for a nominal molecular weight limit (NMWL) of $3 \mathrm{kDa}$. The protein content was determined using Bradford protein assays (Bio-Rad, Hercules, CA, USA). The concentrated media were treated with equivalent volumes of lysis buffer (1\% Triton X-100, 30 mM Tris (pH 8.0), 137 mM sodium chloride, 15\% glycerol and 5 mM EDTA containing 1\% phosphatase inhibitors and $1 \%$ protease inhibitors) to obtain soluble protein samples. Protein samples were boiled with $0.1 \%$ bromophenol blue and $5 \% \beta$-mercaptoethanol for $1 \mathrm{~min}$ at $100^{\circ} \mathrm{C}$, subjected to sodium dodecyl sulfatepolyacrylamide gel electrophoresis (SDS-PAGE) and transferred to a polyvinylidene difluoride membrane (Millipore, Billerica, Massachusetts, USA). The membrane was blocked with 5\% skim milk in Tris-buffered saline/0.1\% Tween 20 buffer (TBS-T) for $30 \mathrm{~min}$ at room temperature and incubated with a 1:1000 dilution of primary antibodies in TBS-T buffer containing $5 \%$ bovine serum albumin (AMRESCO, Solon, Ohio, USA) and $0.02 \%$ sodium azide (Sigma-Aldrich) overnight at $4^{\circ} \mathrm{C}$. The membrane was washed five times for 5 min with TBS-T and incubated with horseradish peroxidase-conjugated secondary antibodies (Santa Cruz Biotechnology, Dallas, Texas, USA) for $1 \mathrm{~h}$ at room temperature. After five washes, the bands were enhanced with chemiluminescence (ECL; Western Detection Kit, Abclon, Seoul, Korea) and detected using a Western imaging (CAS 400SM) system (Davinch-K, Seoul, South Korea). The band intensities were quantified using Image software.

\section{Network analysis}

For gene and protein network analyses, changed genes and proteins with altered expression based on qPCR and Western blot analysis in co-cultured MSCs and adipose-derived SVF cells were analyzed using GeneMANIA (http://www.genemania.org) [23]. Associations between differentially expressed genes and proteins with broadly defined molecular networks were combined and visualized using Cytoscape_v3.3.0. Using the web interface, we predicted protein/gene interactions and their interacting partner proteins identified in this study.

\section{Statistical analysis}

All data were compared via one-way analysis of variance (ANOVA) using the Statistical Package for the Social Sciences (SPSS, version $14.0 \mathrm{~K}$ ) program. The data are expressed as the means \pm SEM. Group means were considered significantly different at $p<0.05$, as determined by the protected least-significant difference (LSD) test when ANOVA indicated an overall significant treatment effect $(p<0.05)$.
Table 2. Sequences of primers used for qPCR. a) F, sequence of sense strands; ${ }^{b}$ R, sequence of anti-sense strands

\begin{tabular}{lcc}
\hline Genes & & Primer sequence (5' - 3') \\
\hline OSX & $\mathrm{F}$ a) & TGCTTGAGGAGGAAGTTCACTATG \\
& $\mathrm{R}$ b) & TGCCCAGAGTTGTTGAGTCC \\
RUNX2 & $\mathrm{F}$ & AAGGGTCCACTCTGGCTTTG \\
& $\mathrm{R}$ & CTAGGCGCATTTCAGGTGCT \\
ALPL & $\mathrm{F}$ & GACCCTTGACCCCCACAAT \\
& $\mathrm{R}$ & CGCCTCGTACTGCATGTCCCCT \\
COL1A1 & $\mathrm{F}$ & CCGGAAACAGACAAGCAACCCAAA \\
& $\mathrm{R}$ & AAAGGAGCAGAAAGGGCAGCATTG \\
COL2A1 & $\mathrm{F}$ & TGGTCTTGGTGGAAACTTTCTGC \\
& $\mathrm{R}$ & AGGTTCACCAGGTTCACCAGGATT \\
OPN & $\mathrm{F}$ & CATATGATGGCCGAGGTGATAG \\
& $\mathrm{R}$ & CATCCAGCTGACTCGTTTCATA \\
OCN & $\mathrm{F}$ & TCACACTCCTCGCCCTATT \\
& $\mathrm{R}$ & TGAAAGCCGATGGTCAG \\
BMP2 & $\mathrm{F}$ & GGAACGGACATTCGGTCCTT \\
& $\mathrm{R}$ & CACCATGGTCGACCTTTAGGA \\
TGFB1 & $\mathrm{F}$ & TGGCGATACCTCAGCAACC \\
Internal control & $\mathrm{R}$ & CTCGTGGATCCACTTCCAG \\
GAPDH & $\mathrm{F}$ & GAAAGCCTGCCGGTGACTAA \\
& $\mathrm{R}$ & AGGAAAAGCATCACCCGGAG
\end{tabular}




\section{Results}

Co-culture of SVF cells and MSCs

To investigate the effects of adiposederived SVF cells on bone marrowderived MSCs, SVF cells were obtained from four donors (Table 1). Isolated SVF cells from human adipose tissues were cultured up to passage 3 when the number of cells had increased sufficiently for co-culturing with MSCs. A previous study using flow cytometry indicated no differences in marker expression in the first three SVF cell passages [24]. Therefore, individual SVF cells at passage 3 were seeded on a trans-well chamber that was inserted into cultured MSCs, and then the differential expression levels of osteogenic genes and protein markers and osteogenic differentiation-inducible genes and proteins were examined over time in mono-cultured MSCs/SVF cells, MSCs co-cultured with SVF cells/SVF cells and CM (Fig. 1A). We first verified that the spindle-shaped morphology of MSCs was altered to an osteoblastlike shape or an increased circular and elongated spindle-shape by SVF cells as time progressed (Fig. 1B). To determine the osteogenic differentiation ability of MSCs co-cultured with SVF cells, MSCs were co-cultivated with SVF cells for up to $48 \mathrm{~h}$ and evaluated by ALP staining and activity during in vitro osteogenic differentiation. As indicated in Figs. 1C and 1D, co-cultivation with SVF cells slightly promoted osteogenic differentiation in MSCs after $24 \mathrm{~h}$ and $48 \mathrm{~h}$. However, the number of ALPstained MSCs and the ALP activity of MSCs, which represent osteogenic differentiation, were not increased in MSCs co-cultured with SVF cells compared with mono-cultured MSCs after $12 \mathrm{~h}$ (data not shown).

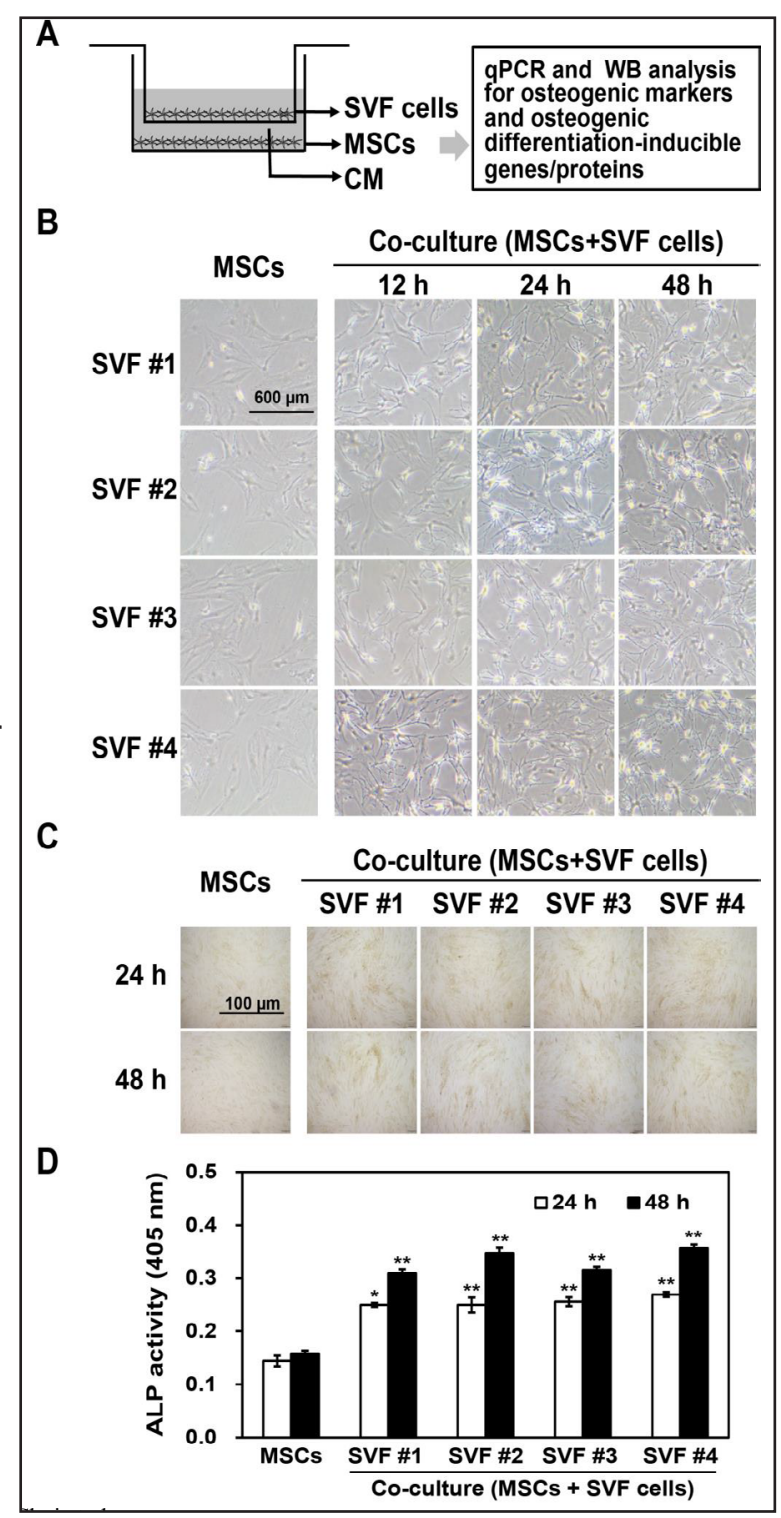

Fig. 1. Experimental scheme of our study (A). Timedependent morphological changes (B) and ALP staining (C) and ALP activity (D) of MSCs co-cultured with SVF cells. The data are representative of three independent experiments. Significant differences among the co-culture groups and the mono-culture group were determined via ANOVA, with $\mathrm{p}$ values indicated as ${ }^{*} \mathrm{p}<0.001$ and ${ }^{* *} \mathrm{p}<0.0001$.

Time-dependent differential regulation of osteogenic genes

On the basis of morphological changes and ALP activity enhancement in MSCs induced by SVF cell treatments, the expression levels of osteoprogenitor markers (osterix (OSX), runtrelated transcription factor 2 (RUNX2), alkaline phosphatase, liver/bone/kidney (ALPL), collagen type I alpha 1 (COL1A1) and COL2A1) and osteoblast markers (ALPL, COL1A1, COL2A2, osteopontin (OPN) and osteocalcin (OCN)) were measured over time using qPCR in mono-cultured MSCs/SVF cells and MSCs co-cultured with SVF cells (Fig. 2). RUNX2/ALPL, COL1A1/OCN, and COL2A1/OPN showed the greatest expression increase at 12, 24 and 48 


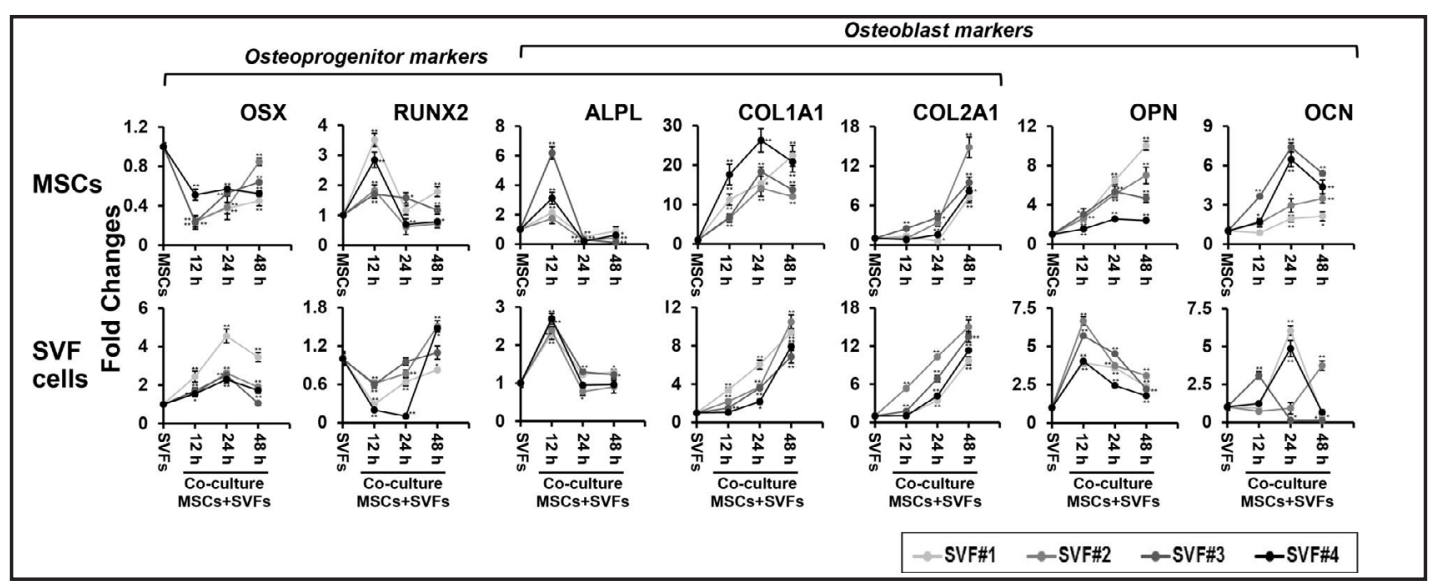

Fig. 2. Time-dependent differential regulation of osteogenic markers in mono-cultured or co-cultured MSCs with SVF cells as determined by qRT-PCR. All values are shown as the normalized target gene expression level (fold change; $2^{-\Delta \Delta \mathrm{Ct}}$ ) relative to GAPDH transcript levels. The data are representative of three independent experiments. Significant differences among the co-culture groups and the mono-culture group were determined via ANOVA, with $\mathrm{p}$ values indicated as ${ }^{*} \mathrm{p}<0.05$ and ${ }^{* *} \mathrm{p}<0.01$.

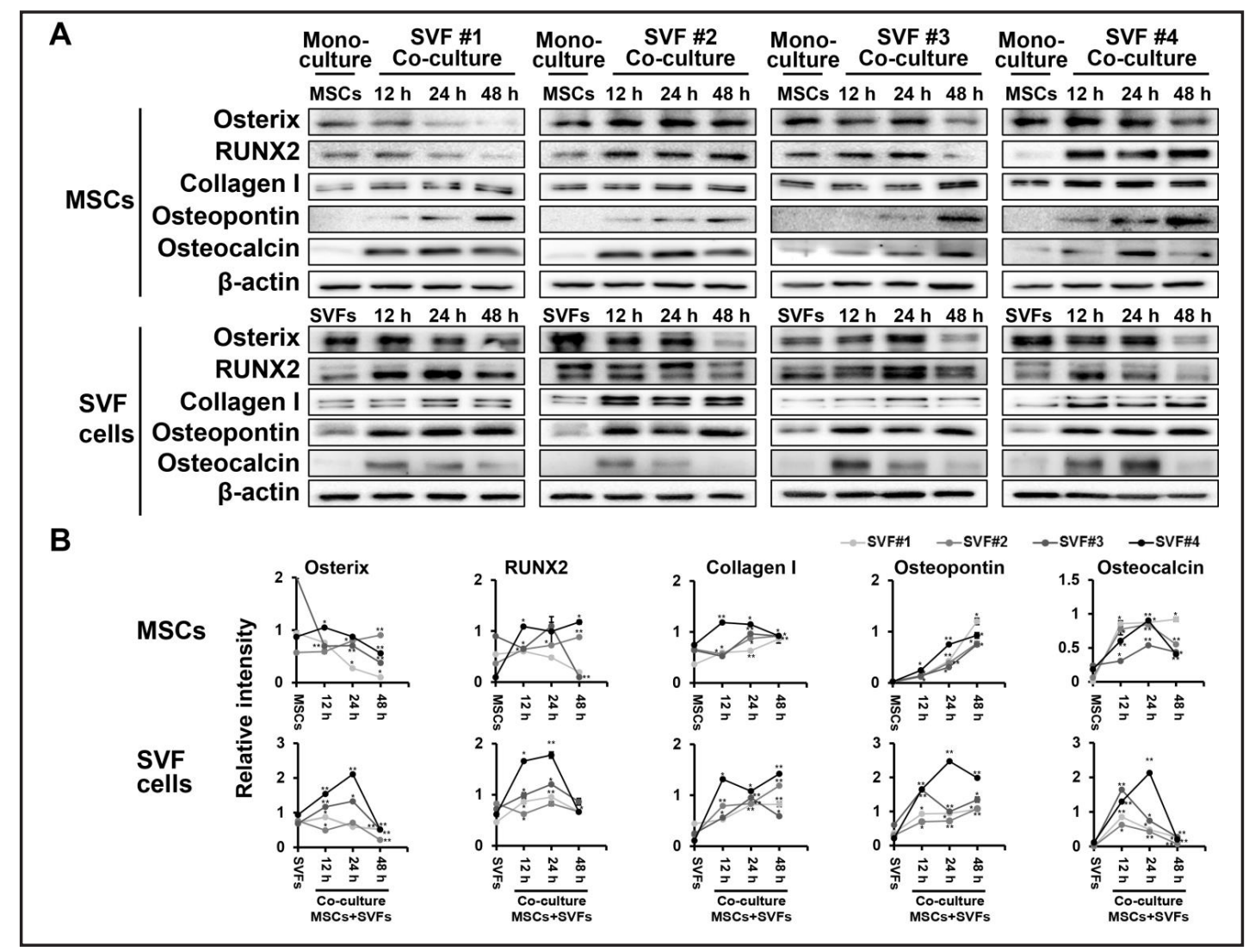

Fig. 3. Time-dependent differential regulation of osteogenic markers in mono-cultured or co-cultured MSCs with SVF cells as determined by Western blot analysis (A). Band intensity was measured as area density and analyzed in ImageJ (B). Relative intensity levels indicate protein levels normalized to $\beta$-actin levels. The data are representative of two independent experiments. Significant differences among the co-culture groups and the mono-culture group were determined via ANOVA, with $p$ values indicated as ${ }^{*} \mathrm{p}<0.05$ and ${ }^{* *} \mathrm{p}<0.01$.

h in MSCs after co-culture (Fig. 2). In contrast, only OSX was down-regulated in MSCs by co-culture with SVF cells (Fig. 2). Meanwhile, ALPL/OPN, OSX/OCN and RUNX2/COL1A1/ 


\section{$\begin{array}{lll}\text { Cellular Physiology } & \text { Cell Physiol Biochem 2017;44:53-65 } \\ \text { DOI: 10.11159/000484582 } & 0 \text { 2017 The Author(s). Published by S. Karger AG, Basel }\end{array}$

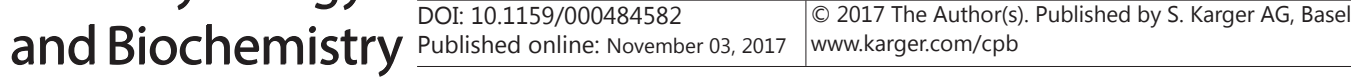 \\ Choi et al.: Rapid Osteogenic Differentiation of Mesenchymal Stem Cells}

COL2A1 showed the largest expression increase at 12, 24 and $48 \mathrm{~h}$ in SVF cells after coculture (Fig. 2). However, at most time points, gene expression levels in MSCs co-cultured with SVF cells were approximately the same or higher than in mono-cultured MSCs, with the exception of OSX or RUNX2 (Fig. 2). In addition, the highest gene expression time points were different between MSCs and co-cultured SVF cells, and the transcript fold changes in MSCs were higher than those in co-cultured SVF cells (Fig. 2). Mono-cultured MSCs, which were used as a control for qPCR analysis, were harvested $24 \mathrm{~h}$ after changing the medium because the differential expression of osteogenic genes was not observed between cells harvested 12, 24 and $48 \mathrm{~h}$ after changing the medium (data not shown).

\section{Time-dependent differential regulation of osteogenic proteins}

In addition to osteogenic genes, osteogenic protein expression over time in the upper layer of cells (SVF cells) and the bottom layer of cells (MSCs) in co-culture conditions was investigated using Western blot analysis (Fig. 3). The osteogenic protein expression was dissimilar to gene expression in many aspects (Fig. 3). There were wider individual variations in osteogenic protein expression than in gene expression, and the time points with the highest osteogenic protein expression were distinct from those observed for gene expression in MSCs and SVF cells under co-culture conditions (Fig. 3). Some proteins in certain SVF cells even showed an expression pattern opposite to the gene expression pattern (Fig. 3). However, the protein expression levels at most of the time points in MSCs and SVF cells under co-culture conditions were approximately the same or higher than those in mono-cultured MSCs and SVF cells (Fig. 3).

Fig. 4. Time-dependent differential regulation of osteogenic differentiation-inducible genes/ proteins in mono-cultured or co-cultured MSCs with SVF cells as determined by qRT-PCR (A), Western blot analysis (B), and network analysis (C). The five yellow circles indicate predicted targets associated with stem cell differentiation. All qPCR values are shown as the normalized target gene expression level (fold change; $2^{-\Delta \Delta \mathrm{ct}}$ ) relative to GAPDH transcript levels. The data are representative of three independent experiments. Significant differences between the co-culture groups and the mono-culture group were determined via ANOVA, with $\mathrm{p}$ values indicated as $* \mathrm{p}<0.05$ and ${ }^{* *} \mathrm{p}<0.01$.

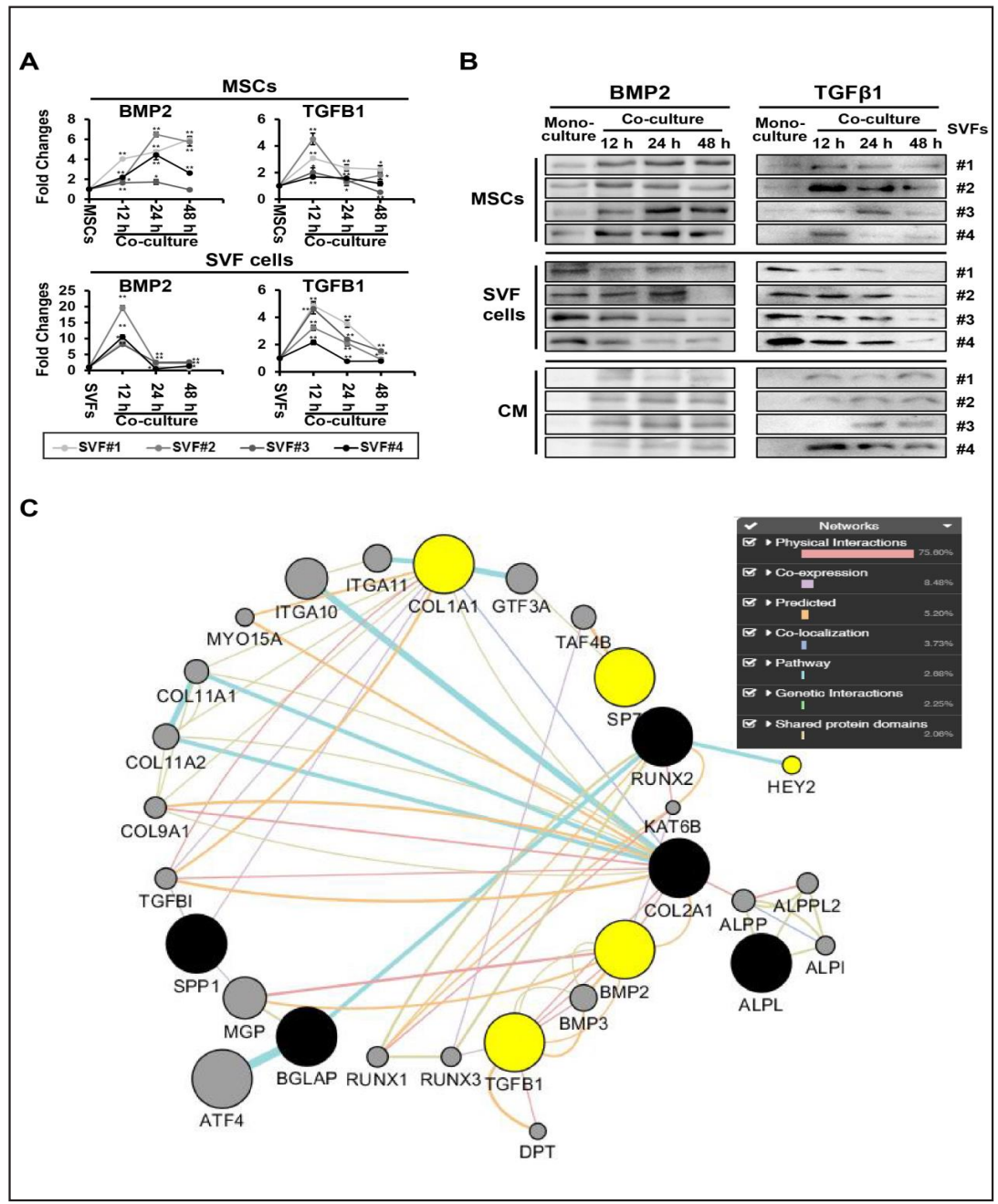




\section{Cellular Physiology Cell Physiol Biochem 2017;44:53-65

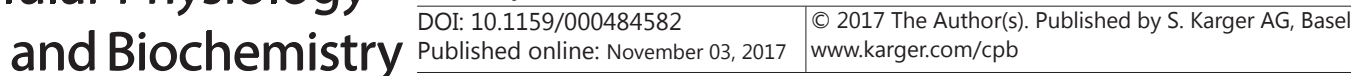 \\ Choi et al.: Rapid Osteogenic Differentiation of Mesenchymal Stem Cells}

Time-dependent differential regulation of osteogenic differentiation-inducible genes/ proteins

Considering the above results, we predicted that proteins secreted by the co-cultured cells would induce osteogenic differentiation and/or comparable effects in both MSCs and SVF cells via paracrine and/or autocrine regulation. The BMPs and TGF $\beta$ have widely recognized critical roles in osteogenesis [25-27]. Therefore, we investigated the gene/protein expression of BMP2 and TGF $\beta 1$ in MSCs, SVF cells and CM (Fig. 4). Surprisingly, BMP2 and TGFB1 transcripts were significantly increased in both MSCs and SVF cells under co-culture conditions (Fig. 4A). BMP2 and TGFB1 in MSCs exhibited the highest expression at $24 \mathrm{~h}$ and 12 $\mathrm{h}$, respectively, but both transcripts in SVF cells exhibited the largest expression increase at $12 \mathrm{~h}$ under co-culture conditions (Fig. 4A). Meanwhile, the protein expression of both BMP2 and TGF $\beta 1$ was similar to the gene expression pattern in MSCs during co-culture with SVFs (Fig. 4B). However, BMP2 and TGF $\beta 1$ protein expression was remarkably decreased in SVF cells from the initial co-cultivation stage, in contrast to the gene expression (Fig. 4B). These results were assumed to be attributed to BMP2 and TGF 31 secretion after the induction of cells via co-culture. As expected, both BMP2 and TGF $\beta 1$ expression levels in CM were significantly up-regulated over time (Fig. 4B). Furthermore, for the prediction of osteogenic differentiation-inducible factors, network analysis using differentially expressed osteogenic markers was performed and, therefore, the relationships between bone morphogenetic proteins (BMP)/transforming growth factor beta (TGF $\beta$ ) and changed osteogenic markers were identified (Fig. 4C). Our data suggest that secreted BMP2 and/or TGF $\beta 1$ proteins from MSCs and SVF cells under co-culture conditions induce osteogenesis and/or a comparable effect via paracrine and/or autocrine regulation.

\section{Discussion}

SVF cells generally consist of blood-derived cells (CD45 ), ASCs (CD31; CD34+, CD45 CD90 ; CD105 and CD106 ), MSCs (CD31; CD34; CD45; CD90 ; CD105 + and CD106 ), endothelial (progenitor) cells (CD31 $1^{+}, \mathrm{CD}^{+} 4^{+}, \mathrm{CD} 45^{-}, \mathrm{CD}^{\circ} 0^{+}, \mathrm{CD} 105^{-}$and $\left.\mathrm{CD}^{\circ} 6^{+}\right)$, vascular smooth muscle cells (CD31; CD34+, CD45, CD90 ${ }^{+}, \mathrm{CD}^{\circ}$ 105 $^{\circ}$ and CD106), pericytes (CD31; CD34, $\mathrm{CD} 45^{\circ}, \mathrm{CD}^{+} 0^{+}, \mathrm{CD} 105^{-}$and $\mathrm{CD} 106^{+}$) and others [28, 29], but the composition differs between laboratories according to the SVF isolation procedure, the age of the patients, downstream processing, etc [30]. In the present study, the SVF cells did not express CD31 and CD34 but expressed CD45, CD90, CD105 and CD106, and the differential expression of surface markers in the first three passages of SVF cells was not observed [24]. These data suggest that the cultured SVF cells contained a heterogeneous cell population and that they may affect other cells and/or be influenced by them through various mechanisms. The relationship between the regenerative capacity and the heterogeneity of SVF cells has been verified in diverse human trials and animal experiments [13], and there is evidence of regenerative activity through cross interactions between different cell populations in the SVF cells and their hosts [13, 31, 32].

In a previous study, we investigated whether SVF cells affected epithelial cells or MSCs that are present in heart tissue to examine the potential benefits of SVF transplantation as a therapy for heart disease in vitro system. We found that epithelial cells co-cultured with SVF cells exhibited enhanced anti-inflammatory and pro-angiogenetic responses under oxidative stress conditions [24], and MSCs co-cultivated with SVF cells ameliorated the apoptosis induced by oxidative stress. Co-culture is a useful and powerful tool to understand cellular interactions and paracrine mechanisms [33], and this method can present a more comprehensive signal for differentiation to a certain lineage; however, it is very difficult to standardize in primary cells due to variation between individual donors [33]. We wondered whether SVF cells also induce the differentiation of MSCs, which are multipotent stromal cells that can differentiate into a variety of cell types. For that reason, we initially examined lineage-specific markers, namely, adipocyte, osteoblast, chondrocyte and myoblast, protein markers, in MSCs co-cultured with SVF cells for $48 \mathrm{~h}$ and found that SVF cells induced only 


\section{Cellular Physiology Cell Physiol Biochem 2017;44:53-65 and BiOChemistry \begin{tabular}{l|l} 
DOI: 10.1159/000484582 & (c) 2017 The Author(s). Published by S. Karger AG, Basel \\
www.karger.com/cpb
\end{tabular} \\ Choi et al.: Rapid Osteogenic Differentiation of Mesenchymal Stem Cells}

the expression of osteogenic differentiation-specific markers in MSCs without inducing expression of other lineage-specific markers. On the basis of preliminary data, we investigated the differential expression of osteogenic markers over time, not only on MSCs co-cultured with SVF cells but also on SVF cells co-cultivated with MSCs. MSCs and SVF cells significantly and mutually induced the expression of osteogenic-specific markers via paracrine and/or autocrine regulation within $48 \mathrm{~h}$ (Figs. 2 and 3). Because this period is very short compared with the typical time required for the in vitro osteogenic differentiation of MSCs [33-35], we could not identify a proper positive osteogenic control and used only negative controls such as mono-cultured MSCs or SVF cells in all experiments.

RUNX2 is expressed in cells prior to the formation of the skeleton, as early as E10.5, at which stage cells still have the capacity to differentiate into osteoblasts or chondrocytes [3638]. RUNX2 is a master transcription factor for osteoblast differentiation, matrix production and mineralization during bone formation [38]. RUNX2 regulates OSX, which is a zinc-fingercontaining transcription factor expressed in osteoblasts that is essential for osteoblast differentiation and bone formation, [39] and ALPL, which is translated into a ubiquitous cellular protein that is an early indicator of cellular activity and differentiation $[40,41]$. RUNX2 also regulates major osteoblast-specific downstream genes, such as COL1A1, OPN and $\mathrm{OCN}$, which determine the osteoblast phenotype and function in skeletogenesis and are translated into matrix proteins [37]. In other words, RUNX2 controls OSX, which may regulate COL1A1, OPN and OCN $[38,42]$. With this connection in mind, in the present study, while RUNX2 and ALPL were significantly increased within $12 \mathrm{~h}$, COL1A1, OPN and OCN were subsequently remarkably up-regulated in MSCs co-cultured with SVF cells isolated from four donors (Fig. 2). Although it was a short period of time, these data closely resembled the expression pattern of osteogenic markers during general osteogenesis. Interestingly, only OSX was significantly decreased in MSCs by SVF cells (Fig. 2). OSX may act downstream and act independently of RUNX2 in osteogenesis [39, 43]. These results suggest that the co-cultivation of MSCs with SVF cells may rapidly induce osteogenesis and/or comparable effects through a RUNX2-dependent and OSX-independent mechanism.

The expression of osteogenic-specific genes and proteins induced by the co-culture of MSCs and SVF cells showed differences, especially in early markers such as RUNX2, osterix and collagen I (Fig. 3). These results were believed to result from differences between gene and protein expression. Gene expression is often interpreted in terms of protein levels, but the correlation can be as little as $40 \%$ depending on the system [44]. Therefore, the differences between gene and protein expression were likely due to various causes, including RNA stability and processing and protein stability and modification [44]. Moreover, RUNX2 mRNA levels were constitutively expressed, but a distinct lack of correlation between RUNX2 mRNA and protein levels was observed, indicating that RUNX2 may be regulated at multiple levels, including changes in mRNA and protein levels [45].

BMPs/TGF $\beta$ have widely recognized roles in bone formation during mammalian development and multiple functions in the body [25-27]. Autocrine and paracrine stimulation with TGF $\beta$ is critical in maintenance and expansion of MSCs and osteoblast progenitors [46], and osteoblast-enriched populations are more sensitive to its mitogenic effect than other populations at earlier developmental stages [47]. TGF $\beta$ signaling also promotes osteoprogenitor proliferation, early differentiation, commitment to the osteoblastic lineage and cooperation between BMPs and TGF $\beta$ [26]. The BMP signaling pathway is also involved in various stages of the developmental process, such as osteoblast differentiation, mesoderm patterning and bone formation [27]. BMP is required for MSC differentiation into osteochondroprogenitor cells, which are able to differentiate into chondrocytes and osteoblasts [27], and for the secretion by differentiated osteoblasts of the matrix upon which bone formation occurs [48]. In particular, BMP2 can induce the up-regulation of critical osteogenic regulators [27]. Therefore, we predicted that BMP2 and/or TGF $\beta$ may be osteogenic differentiation-inducible factors of co-cultured MSCs and SVF cells. Surprisingly, BMP2 and TGF $\beta 1$ were significantly secreted by MSCs and SVF cells during co-cultivation (Fig. 4). 
ASCs have been demonstrated to be highly efficient in inducing bone generation and healing in animal studies [17] as well as in human clinical trials [49, 50]. ASCs seeded in a scaffold of beta-tricalcium phosphate ( $\beta$-TCP) implanted into four patients using a cranioplasty procedure achieved successful ossification without complications [49]. Placing $\beta$-TCP, BMP2 and ASCs into an anterior mandibular defect also induced sufficient ossification [50], and ASCs injected into bone defects appeared to accelerate bone healing [51]. In addition, several studies of SVF application for bone generation have been reported [19, 52 ,53]. Recombinant BMP2 stimulated osteoblastic differentiation in SVF cells to generate ectopic bone tissue [52], and SVF and ASCs seeded in a scaffold demonstrated a high degree of regeneration in osteochondral defects [19]. SVF supplementation on bone substitutes for maxillary sinus floor elevation (MSFE) showed potential effectiveness for bone formation [53]. The application of SVF cells and/or ASCs is a promising approach for the treatment of bone defects, although it is still in the experimental phase [30].

In summary, we found that bone marrow-derived MSCs and adipose-derived SVF cells significantly and mutually induced the expression of osteogenic-specific markers via paracrine and/or autocrine regulation through BMP2 and/or TGF $\beta 1$ but did not induce adipocyte, chondrocyte or myoblast marker expression. Osteogenesis and/or comparable effects were rapidly induced within $48 \mathrm{~h}$. Our findings suggest that the positive effects of SVF implantation into impaired bone may be attributed to the rapid induction of MSC osteogenesis and that the transplantation of co-cultivated and preconditioned SVF cells and/or MSCs may be more effective than the transplantation of untreated cells to treat bone defects.

\section{Abbreviations}

ALP (alkaline phosphatase); ASCs (adipose-derived stem cells); CM (conditioned medium); MSCs (mesenchymal stem cells); qPCR (quantitative real-time PCR); SVF (stromal vascular fraction).

\section{Acknowledgements}

This study was supported by a Korea Science and Engineering Foundation grant funded by the Korean government (MEST) (NRF-2015M3A9E6029519).

\section{Disclosure Statement}

The authors declare that they have no competing interests to disclose.

\section{References}

1 Van den Bos C, Mosca JD, Winkles J, Kerrigan L, Burgess WH, Marshak DR: Human mesenchymal stem cells respond to fibroblast growth factors. Hum Cell 1997;10:45-50.

-2 Alessandri G, Pagano S, Bez A, Benetti A, Pozzi S, Iannolo G, Baronio M, Invernici G, Caruso A, Muneretto C, Bisleri G, Parati E: Isolation and culture of human muscle-derived stem cells able to differentiate into myogenic and neurogenic cell lineages. Lancet 2004;364:1872-1883.

3 Barry FP, Murphy JM: Mesenchymal stem cells: clinical applications and biological characterization. Int J Biochem Cell Biol 2004;36:568-584.

4 De Bari C, Dell'Accio F, Tylzanowski P, Luyten FP: Multipotent mesenchymal stem cells from adult human synovial membrane. Arthritis Rheum 2001;44:1928-1942. 


\section{Cellular Physiology Cell Physiol Biochem 2017;44:53-65 \begin{tabular}{l|l} 
DOI: 10.1159/000484582 & (C) 2017 The Author(s). Published by S. Karger AG, Basel
\end{tabular} and Biochemistry

5 Raida M, Heymann AC, Gunther C, Niederwieser D: Role of bone morphogenetic protein 2 in the crosstalk between endothelial progenitor cells and mesenchymal stem cells. Int J Mol Med 2006;18:735-739.

6 Lee YS, Lee JE, Park HY, Lim YS, Lee JC, Wang SG, Lee BJ: Isolation of mesenchymal stromal cells (MSCs) from human adenoid tissue. Cell Physiol Biochem 2013;31:513-524.

-7 Via AG, Frizziero A, Oliva F: Biological properties of mesenchymal Stem Cells from different sources. Muscles Ligaments Tendons J 2012;2:154-162.

-8 Bernardo ME, Locatelli F, Fibbe WE: Mesenchymal stromal cells. Ann N Y Acad Sci 2009;1176:101-117.

-9 Choi JW, Kim KE, Lee CY, Lee J, Seo HH, Lim KH, Choi E, Lim S, Lee S, Kim SW, Hwang KC: Alterations in Cardiomyocyte Differentiation-Related Proteins in Rat Mesenchymal Stem Cells Exposed to Hypoxia. Cell Physiol Biochem 2016;39:1595-1607.

10 Song SW, Kim KE, Choi JW, Lee CY, Lee J, Seo HH, Lim KH, Lim S, Lee S, Kim SW, Hwang KC: Proteomic Analysis and Identification of Paracrine Factors in Mesenchymal Stem Cell-Conditioned Media under Hypoxia. Cell Physiol Biochem 2016;40:400-410.

-11 Fehrer C, Brunauer R, Laschober G, Unterluggauer H, Reitinger S, Kloss F, Gully C, Gassner R, Lepperdinger G: Reduced oxygen tension attenuates differentiation capacity of human mesenchymal stem cells and prolongs their lifespan. Aging Cell 2007;6:745-757.

12 Charbord P, Livne E, Gross G, Haupl T, Neves NM, Marie P, Bianco P, Jorgensen C: Human bone marrow mesenchymal stem cells: a systematic reappraisal via the genostem experience. Stem Cell Rev 2011;7:3242.

13 Guo J, Nguyen A, Banyard DA, Fadavi D, Toranto JD, Wirth GA, Paydar KZ, Evans GR, Widgerow AD: Stromal vascular fraction: A regenerative reality? Part 2: Mechanisms of regenerative action. J Plast Reconstr Aesthet Surg 2016;69:180-188.

14 Nguyen A, Guo J, Banyard DA, Fadavi D, Toranto JD, Wirth GA, Paydar KZ, Evans GR, Widgerow AD: Stromal vascular fraction: A regenerative reality? Part 1: Current concepts and review of the literature. J Plast Reconstr Aesthet Surg 2016;69:170-179.

15 Zuk PA, Zhu M, Mizuno H, Huang J, Futrell JW, Katz AJ, Benhaim P, Lorenz HP, Hedrick MH: Multilineage cells from human adipose tissue: implications for cell-based therapies. Tissue Eng 2001;7:211-228.

16 Bourin P, Bunnell BA, Casteilla L, Dominici M, Katz AJ, March KL, Redl H, Rubin JP, Yoshimura K, Gimble JM: Stromal cells from the adipose tissue-derived stromal vascular fraction and culture expanded adipose tissue-derived stromal/stem cells: a joint statement of the International Federation for Adipose Therapeutics and Science (IFATS) and the International Society for Cellular Therapy (ISCT). Cytotherapy 2013;15:641-648.

17 Chung MT, Zimmermann AS, Paik KJ, Morrison SD, Hyun JS, Lo DD, McArdle A, Montoro DT, Walmsley GG, Senarath-Yapa K, Sorkin M, Rennert R, Chen HH, Chung AS, Vistnes D, Gurtner GC, Longaker MT, Wan DC: Isolation of human adipose-derived stromal cells using laser-assisted liposuction and their therapeutic potential in regenerative medicine. Stem Cells Transl Med 2013;2:808-817.

>18 Riordan NH, Ichim TE, Min WP, Wang H, Solano F, Lara F, Alfaro M, Rodriguez JP, Harman RJ, Patel AN, Murphy MP, Lee RR, Minev B: Non-expanded adipose stromal vascular fraction cell therapy for multiple sclerosis. J Transl Med 2009; 7:29.

19 Jurgens WJ, Kroeze RJ, Zandieh-Doulabi B, van Dijk A, Renders GA, Smit TH, van Milligen FJ, Ritt MJ, Helder MN: One-step surgical procedure for the treatment of osteochondral defects with adipose-derived stem cells in a caprine knee defect: a pilot study. Biores Open Access 2013;2:315-325.

20 van Dijk A, Naaijkens BA, Jurgens WJ, Nalliah K, Sairras S, van der Pijl RJ, Vo K, Vonk AB, van Rossum AC, Paulus WJ, van Milligen FJ, Niessen HW: Reduction of infarct size by intravenous injection of uncultured adipose derived stromal cells in a rat model is dependent on the time point of application. Stem Cell Res 2011;7:219-229.

21 Semon JA, Zhang X, Pandey AC, Alandete SM, Maness C, Zhang S, Scruggs BA, Strong AL, Sharkey SA, Beuttler MM, Gimble JM, Bunnell BA: Administration of murine stromal vascular fraction ameliorates chronic experimental autoimmune encephalomyelitis. Stem Cells Transl Med 2013;2:789-796.

-22 Han S, Sun HM, Hwang KC, Kim SW: Adipose-Derived Stromal Vascular Fraction Cells: Update on Clinical Utility and Efficacy. Crit Rev Eukaryot Gene Expr 2015;25:145-152. 


\section{Cellular Physiology Cell Physiol Biochem 2017;44:53-65

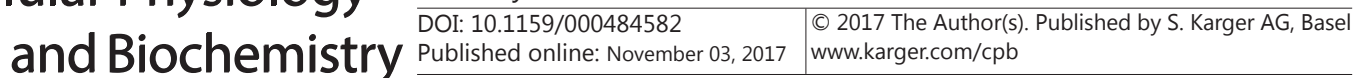

Choi et al.: Rapid Osteogenic Differentiation of Mesenchymal Stem Cells

23 Warde-Farley D, Donaldson SL, Comes O, Zuberi K, Badrawi R, Chao P, Franz M, Grouios C, Kazi F, Lopes CT, Maitland A, Mostafavi S, Montojo J, Shao Q Wright G, Bader GD, Morris Q: The GeneMANIA prediction server: biological network integration for gene prioritization and predicting gene function. Nucleic Acids Res 2010;38:W214-220.

24 Lim S, Kim IK, Choi JW, Seo HH, Lim KH, Lee S, Lee HB, Kim SW, Hwang KC: Gender-dimorphic effects of adipose-derived stromal vascular fractions on HUVECs exposed to oxidative stress. Int J Med Sci 2017;14:911-919.

-25 Katagiri T, Takahashi N: Regulatory mechanisms of osteoblast and osteoclast differentiation. Oral Dis 2002;8:147-159.

26 Chen G, Deng C, Li YP: TGF-beta and BMP signaling in osteoblast differentiation and bone formation. Int J Biol Sci 2012;8:272-288.

27 Beederman M, Lamplot JD, Nan G, Wang J, Liu X, Yin L, Li R, Shui W, Zhang H, Kim SH, Zhang W, Zhang J, Kong Y, Denduluri S, Rogers MR, Pratt A, Haydon RC, Luu HH, Angeles J, Shi LL, He TC: BMP signaling in mesenchymal stem cell differentiation and bone formation. J Biomed Sci Eng 2013;6:32-52.

-28 Lin K, Matsubara Y, Masuda Y, Togashi K, Ohno T, Tamura T, Toyoshima Y, Sugimachi K, Toyoda M, Marc H, Douglas A: Characterization of adipose tissue-derived cells isolated with the Celution system. Cytotherapy 2008;10:417-426.

29 Yoshimura K, Shigeura T, Matsumoto D, Sato T, Takaki Y, Aiba-Kojima E, Sato K, Inoue K, Nagase T, Koshima I, Gonda K: Characterization of freshly isolated and cultured cells derived from the fatty and fluid portions of liposuction aspirates. J Cell Physiol 2006;208:64-76.

-30 Bora P, Majumdar AS: Adipose tissue-derived stromal vascular fraction in regenerative medicine: a brief review on biology and translation. Stem Cell Res Ther 2017;8:145.

-31 Varma MJ, Breuls RG, Schouten TE, Jurgens WJ, Bontkes HJ, Schuurhuis GJ, van Ham SM, van Milligen FJ: Phenotypical and functional characterization of freshly isolated adipose tissue-derived stem cells. Stem Cells Dev 2007;16:91-104.

-32 Blaber SP, Webster RA, Hill CJ, Breen EJ, Kuah D, Vesey G, Herbert BR: Analysis of in vitro secretion profiles from adipose-derived cell populations. J Transl Med 2012;10:172.

33 Kim KI, Park S, Im GI: Osteogenic differentiation and angiogenesis with cocultured adipose-derived stromal cells and bone marrow stromal cells. Biomaterials 2014;35:4792-4804.

-34 Hoemann CD, El-Gabalawy H, McKee MD: In vitro osteogenesis assays: influence of the primary cell source on alkaline phosphatase activity and mineralization. Pathol Biol (Paris) 2009;57:318-323.

-35 Calabrese G, Giuffrida R, Fabbi C, Figallo E, Lo Furno D, Gulino R, Colarossi C, Fullone F, Giuffrida R, Parenti R, Memeo L, Forte S: Collagen-Hydroxyapatite Scaffolds Induce Human Adipose Derived Stem Cells Osteogenic Differentiation In vitro. PLoS One 2016;11:e0151181.

-36 Ducy P: Cbfa1: a molecular switch in osteoblast biology. Dev Dyn 2000;219:461-471.

-37 Ducy P, Zhang R, Geoffroy V, Ridall AL, Karsenty G: Osf2/Cbfa1: a transcriptional activator of osteoblast differentiation. Cell 1997;89:747-754.

-38 Liu TM, Lee EH: Transcriptional regulatory cascades in Runx2-dependent bone development. Tissue Eng Part B Rev 2013;19:254-263.

-39 Nakashima K, Zhou X, Kunkel G, Zhang Z, Deng JM, Behringer RR, de Crombrugghe B: The novel zinc fingercontaining transcription factor osterix is required for osteoblast differentiation and bone formation. Cell 2002;108:17-29.

-40 Shui C, Spelsberg TC, Riggs BL, Khosla S: Changes in Runx2/Cbfa1 expression and activity during osteoblastic differentiation of human bone marrow stromal cells. J Bone Miner Res 2003;18:213-221.

-41 Hu H, Chen M, Dai G, Du G, Wang X, He J, Zhao Y, Han D, Cao Y, Zheng Y, Ding D: An Inhibitory Role of Osthole in Rat MSCs Osteogenic Differentiation and Proliferation via Wnt/beta-Catenin and Erk1/2-MAPK Pathways. Cell Physiol Biochem 2016;38:2375-2388.

42 Xiao WL, Zhang DZ, Fan CH, Yu BJ: Intermittent Stretching and Osteogenic Differentiation of Bone Marrow Derived Mesenchymal Stem Cells via the p38MAPK-Osterix Signaling Pathway. Cell Physiol Biochem 2015;36:1015-1025.

-43 Harada H, Tagashira S, Fujiwara M, Ogawa S, Katsumata T, Yamaguchi A, Komori T, Nakatsuka M: Cbfa1 isoforms exert functional differences in osteoblast differentiation. J Biol Chem 1999;274:6972-6978.

44 Vogel C, Marcotte EM: Insights into the regulation of protein abundance from proteomic and transcriptomic analyses. Nat Rev Genet 2012;13:227-232. 


\section{Cellular Physiology Cell Physiol Biochem 2017;44:53-65 \begin{tabular}{l|l} 
DOI: 10.1159/000484582 & $\begin{array}{l}\text { O 2017 The Author(s). Published by S. Karger AG, Basel } \\
\text { www.karger.com/cpb }\end{array}$ \\
\hline
\end{tabular}}

Choi et al.: Rapid Osteogenic Differentiation of Mesenchymal Stem Cells

45 Sudhakar S, Li Y, Katz MS, Elango N: Translational regulation is a control point in RUNX2/Cbfa1 gene expression. Biochem Biophys Res Commun 2001;289:616-622.

46 Derynck R, Akhurst RJ: Differentiation plasticity regulated by TGF-beta family proteins in development and disease. Nat Cell Biol 2007;9:1000-1004.

47 Centrella M, Ji C, McCarthy TL: Control of TGF-beta receptor expression in bone. Front Biosci 1998;3:d113124.

48 Karsenty G: The genetic transformation of bone biology. Genes Dev 1999;13:3037-3051.

49 Thesleff T, Lehtimaki K, Niskakangas T, Mannerstrom B, Miettinen S, Suuronen R, Ohman J: Cranioplasty with adipose-derived stem cells and biomaterial: a novel method for cranial reconstruction. Neurosurgery 2011;68:1535-1540.

50 Sandor GK, Tuovinen VJ, Wolff J, Patrikoski M, Jokinen J, Nieminen E, Mannerstrom B, Lappalainen OP, Seppanen R, Miettinen S: Adipose stem cell tissue-engineered construct used to treat large anterior mandibular defect: a case report and review of the clinical application of good manufacturing practice-level adipose stem cells for bone regeneration. J Oral Maxillofac Surg 2013;71:938-950.

51 Wilson SM, Goldwasser MS, Clark SG, Monaco E, Bionaz M, Hurley WL, Rodriguez-Zas S, Feng L, Dymon Z, Wheeler MB: Adipose-derived mesenchymal stem cells enhance healing of mandibular defects in the ramus of swine. J Oral Maxillofac Surg 2012;70:e193-203.

52 Mehrkens A, Saxer F, Guven S, Hoffmann W, Muller AM, Jakob M, Weber FE, Martin I, Scherberich A: Intraoperative engineering of osteogenic grafts combining freshly harvested, human adipose-derived cells and physiological doses of bone morphogenetic protein-2. Eur Cell Mater 2012;24:308-319.

53 Prins HJ, Schulten EA, Ten Bruggenkate CM, Klein-Nulend J, Helder MN: Bone Regeneration Using the Freshly Isolated Autologous Stromal Vascular Fraction of Adipose Tissue in Combination With Calcium Phosphate Ceramics. Stem Cells Transl Med 2016;5:1362-1374. 